\title{
Identification and Characterization of the Feeding Circuit-Activating Peptides, a Novel Neuropeptide Family of Aplysia
}

\author{
J. V. Sweedler, ${ }^{1}$ L. Li, ${ }^{1}$ S. S. Rubakhin, ${ }^{1}$ V. Alexeeva, ${ }^{2}$ N. C. Dembrow, ${ }^{2}$ O. Dowling, ${ }^{2}$ J. Jing, ${ }^{2}$ K. R. Weiss, ${ }^{2}$ and \\ F. S. Vilim ${ }^{2}$ \\ ${ }^{1}$ Department of Chemistry and Beckman Institute, University of Illinois, Urbana, Illinois 61801, and 2Department of \\ Physiology and Biophysics, Mount Sinai School of Medicine, New York, New York 10029
}

\begin{abstract}
We use a multidisciplinary approach to identify, map, and characterize the bioactivity of modulatory neuropeptides in the circuitry that generates feeding behavior in Aplysia. Matrixassisted laser desorption/ionization time-of-flight mass spectrometry of the cerebral-buccal connective (CBC), a nerve containing axons of many interneurons that control feeding behavior of Aplysia, was used to identify neuropeptides that may participate in generation and shaping of feeding motor programs. Using this functionally oriented search, we identified a novel family of peptides that we call the feeding circuitactivating peptides (FCAPs). Two peptides with masses identical to those observed in the CBCs (molecular weight 1387 and 1433) were purified from buccal ganglia and partially sequenced using mass spectrometry. The amino acid sequence was then used to clone the FCAP precursor, which encodes multiple copies of eight different FCAPs. The two FCAPs present in highest copy number correspond to those observed
\end{abstract}

in the CBC. The distribution of FCAP expression was mapped using Northern analysis, whole-mount in situ hybridization, and immunocytochemistry. Consistent with our initial findings, FCAP-immunopositive axons were observed in the CBC. Furthermore, we found that FCAP was present in some cerebralbuccal and buccal-cerebral interneurons. As their name suggests, FCAPs are capable of initiating rhythmic feeding motor programs and are the first neuropeptides with such activity in this circuit. The actions of FCAPs suggest that these peptides may contribute to the induction and maintenance of foodinduced arousal. FCAPs were also localized to several other neuronal systems, suggesting that FCAPs may play a role in the regulation of multiple behaviors.

Key words: MALDI-TOF MS; Aplysia californica; cDNA cloning; neuropeptide processing; in situ hybridization; immunocytochemistry; feeding behavior
In addition to classical neurotransmitters, many neurons also contain modulatory neuropeptides that exert important and widespread actions in the nervous system and peripheral tissues (Strand, 1999). One of the preparations in which growing evidence indicates that peptidergic modulation plays an important role in initiation and regulation of behavior is Aplysia, in which neural circuits that mediate the consummatory phase of feeding behaviors are subject to extensive peptidergic modulation (Sossin et al., 1987; Xin et al., 1999; Morgan et al., 2000, 2002; Furukawa et al., 2001; Jing and Weiss, 2001). Previous work that has characterized some of the peptides in the feeding circuitry was performed on peptides that were originally identified from peripheral tissues or from other systems (Price and Greenberg, 1977; Morris et al., 1982; Cropper et al., 1987, 1988; Phares and Lloyd, 1996; Phares et al., 1996). Here we report a functionally oriented strategy that focuses on the cerebral-buccal connectives (CBCs), nerves whose integrity is required for generating feeding behavior (Kupfermann, 1974a), to identify additional neuropeptides.

Received March 12, 2002; revised June 13, 2002; accepted June 14, 2002.

This work was supported by National Institutes of Health (NIH) Grants DA13330, NS31609, MH50235, and K05MH01427, and National Science Foundation Grant CHE 98-77071. We gratefully acknowledge the generous gift of Aplysia cDNA libraries from Dr. Gregg Nagle and Dr. Wayne Sossin. We also thank Dr. E. C. Cropper for critical reading of this manuscript. Aplysia californica were partially provided by the National Resource for Aplysia at the University of Miami under NIH National Center for Research Resources Grant RR10294.

Correspondence should be addressed to F. S. Vilim, Box 1218, Department of Physiology and Biophysics, Mount Sinai School of Medicine, New York, NY 10029. E-mail: vilim@inka.mssm.edu.

Copyright (C) 2002 Society for Neuroscience $\quad 0270-6474 / 02 / 227797-12 \$ 15.00 / 0$
The CBCs contain the axons of many interneurons that play important roles in the generation of feeding motor programs that are implemented by the cerebral and buccal ganglia (Rosen et al., 1991). These neurons include the cerebral-buccal interneurons (CBIs) and buccal-cerebral interneurons (BCIs), which are known to be involved in generating and shaping the cerebral and buccal ganglion-mediated components of feeding motor programs (Rosen et al., 1991; Teyke et al., 1993; Hurwitz et al., 1997; Perrins and Weiss, 1998; Xin et al., 1999). Modulators that can alter feeding motor program output have been localized to some of the known CBIs and BCIs, and evidence suggests that additional, as yet unidentified neuropeptides are present in the feeding circuitry (Lloyd, 1989; Li et al., 1998). Identification of modulatory peptides that are present in the feeding circuitry is an important step toward understanding the cellular basis of feeding behaviors.

To identify neuropeptides that may be present in the feeding circuitry, we undertook to characterize neuropeptides that are actively transported from neuronal somata to terminals via the CBCs. We initially targeted the CBCs instead of individual CBIs and BCIs to provide a more global analysis of peptides that may function in feeding. In addition, targeting the CBCs should include some uncharacterized elements of the feeding circuitry, thereby potentially enabling their identification. We exploited the high sensitivity and precision of matrix-assisted laser desorption/ ionization (MALDI) time-of-flight mass spectrometry (TOF MS) (Hillenkamp et al., 1991; Kaufmann, 1995; Li et al., 1998) to detect the presence of unique molecular masses that corre- 
sponded to specific peptides transported in the CBC, and we analyzed the directionality of that transport. Using MALDIdirected purification and sequencing, we identified two novel peptides that were detected in the CBCs. We named these structurally related neuropeptides the feeding circuit-activating peptides (FCAPs) because of their ability to initiate organized rhythmic motor output of the feeding circuit.

\section{MATERIALS AND METHODS}

Animals. Aplysia californica (100-350 gm) were obtained from Aplysia Research Facility (Miami, FL), Pacific Biomarine (Venice, CA), and Marinus Inc. (Long Beach, CA). Animals were maintained in aerated seawater tanks at $14^{\circ} \mathrm{C}$.

Cloning. Standard molecular techniques (Sambrook et al., 1989) were used, except where noted. Semi-nested rapid amplification of cDNA ends (RACE) was performed as described previously (Fujisawa et al., 1999; Furukawa et al., 2001). Briefly, two bluescript primers (BS1 = ACCATGATTACGCCAAG and then BS2 = AATTAACCCTCACTAAAG) were used sequentially with a single degenerate oligo (GAY WSY ITI GGI GGI TTY GAR GTI CA), designed to a partial sequence of the 1387 peptide, in PCR on a random-primed Aplysia CNS cDNA $\lambda$ library. The PCR products were ligated into T/A cloning vector (Invitrogen, Carlsbad, CA) and sequenced using dye termination. Once a correct clone was obtained, library screening and RACE were subsequently used to determine the consensus (derived from at least three clones) coding sequence of the precursor.

Northern analysis. Northern analysis were performed as described previously (Fujisawa et al., 1999; Furukawa et al., 2001). Briefly, blots were hybridized overnight at $50^{\circ} \mathrm{C}$ with $\left[{ }^{32} \mathrm{P}\right] \mathrm{dCTP}$-labeled FCAP cDNA, washed, and exposed to film. Autoradiographs were scanned into Photoshop and compiled to generate the final figure.

In situ hybridization. In situ hybridization (ISH) on Aplysia CNS was performed as described previously (Vilim et al., 2001). Briefly, fixed desheathed ganglia were hybridized with digoxigenin-labeled cRNA and detected with alkaline phosphatase nitroblue and tetrazolium/5-bromo4-chloro-3-indolyl-phosphate (Roche Molecular Biochemicals, Indianapolis, IN). The stained ganglia were photographed using a Nikon CoolPix 990 camera mounted on a Nikon microscope (Morrell Instruments, Melville, NY). Digital photographs were imported into Photoshop (Adobe Systems, San Jose, CA) to generate final figures.

Antibodies. The rabbit anti-small cardioactive peptide (SCP) antibody was a gift from Dr. Richard Scheller (GeneTech, San Francisco, CA). Antibodies to FCAP were generated in rats as described previously (Fujisawa et al., 1999; Furukawa et al., 2001), but using FCAPb (ALDSLGGFQVHGW; Protein Core Facility, University of Illinois, Urbana, IL) coupled to BSA (Sigma A0281) using 1-ethyl-3(dimethylaminopropyl)carbodiimide (Sigma E7750). Testing of the rat FCAP antibodies showed that immunostaining was abolished by preincubation with $10^{-4} \mathrm{M}$ ALDSLGGFQVHGW (data not shown).

Immunocytochemistry. Immunocytochemistry (IMM) was performed on whole mounts as described previously (Vilim et al., 1996; Fujisawa et al., 1999; Furukawa et al., 2001). Briefly, fixed tissues were exposed to primary antibodies $(4-7 \mathrm{~d})$, washed for $2 \mathrm{~d}$, and exposed to secondary antibodies for $2-3 \mathrm{~d}$. The longer incubations and washes used here have been found to improve the signal-to-noise ratio in our whole mounts. The tissues were photographed on a Nikon microscope equipped with epifluorescence (Morrell Instruments) and compiled into figures using Photoshop.

Backfills. Backfills were performed as described previously (Furukawa et al., 2001). Briefly, CBCs were backfilled overnight with $1 \%$ biocytin and processed for immunocytochemistry as described above, with the addition of streptavidin-fluorescein to develop the backfilled neurons.

Mass spectrometry. MALDI-TOF MS of neurons was performed as described previously (Garden et al., 1996; Fujisawa et al., 1999; Furukawa et al., 2001). Analysis of the CBCs was done on short sections $(<1 \mathrm{~mm})$ of the desheathed cut ends of CBCs after varying periods of incubation in Leibovitz's L-15 media (Life Technologies). Mass spectra were obtained using two spectrometers, Voyager Elite and Voyager DE STR equipped with delayed ion extraction (PE Biosystems, Framingham, MA). Each unsmoothed mass spectrum is the average of 64-128 laser pulses. Mass calibration was performed externally using either bovine insulin (Sigma) and synthetic Aplysia $\alpha$-bag cell peptide (American Peptide, Sunnyvale, CA) or a previously calibrated mass spectrum obtained from bag cells (Garden et al., 1998).
MALDI post-source decay analysis. Peptides extracted from 110 buccal ganglia (Floyd et al., 1999) were fractionated into 45 samples using microbore HPLC. Mixtures of equal volumes of LC fractions and matrix solution were subjected to MALDI using previously described methods (Floyd et al., 1999). For MALDI post-source decay (PSD) analysis, the matrix $\alpha$-cyano-4-hydroxycinnamic acid $(10 \mathrm{mg} / \mathrm{ml}$ in $6: 3: 1$ acetonitrile/ water $/ 3 \%$ trifluoroacetic acid) (Aldrich, Milwaukee, WI) was used. Positive-ion mass spectra were acquired using reflectron mode. The total acceleration voltage was $20 \mathrm{kV}$, grid voltage was at $75 \%$, guide-wire voltage was at $0.03 \%$, and a delay time of $75 \mathrm{nsec}$ was used. Spectra were obtained by accumulating data from 100-256 laser shots. To obtain complete PSD spectra, a series of reflectron mass spectral segments were acquired, each optimized to focus fragment ions within different mass/ charge $(\mathrm{m} / \mathrm{z})$ ranges (Spengler, 1997). Each segment was stitched together using the Biospectrometry Workstation software to generate a composite PSD spectrum.

Electrophysiology. Physiological activity of FCAP was tested in a preparation that consisted of the isolated cerebral and buccal ganglia with CBCs intact. Both ganglia were desheathed to expose the cells of interest. Conventional intracellular recordings were made with glass microelectrodes filled with $2 \mathrm{M} \mathrm{KAc}$ and beveled to 8-15 $\mathrm{M} \Omega$. Extracellular recordings were made with suction electrodes that were manufactured from polyethylene tubing. Ganglia were then pinned out in a Sylgardlined dish that had a volume of $\sim 1.5 \mathrm{ml}$. The preparation was perfused continuously with artificial seawater (ASW) composed of (in mM): 460 $\mathrm{NaCl}, 10 \mathrm{KCl}, 55 \mathrm{MgCl}_{2}, 11 \mathrm{CaCl}_{2}$, and 10 HEPES buffer, $\mathrm{pH}$ 7.6, at a rate of $0.3 \mathrm{ml} / \mathrm{min}$, and cooled to $14-17^{\circ} \mathrm{C}$. Peptides were applied by replacing the ASW perfusate with a perfusate consisting of ASW with freshly dissolved peptides.

\section{RESULTS}

\section{MALDI-TOF MS of the cerebral-buccal connective}

We used MALDI to identify the neuropeptides that were present in the $\mathrm{CBC}$, a nerve whose integrity is critical for the generation of the consummatory phase of feeding behavior. Analysis of the $\mathrm{CBC}$ with MALDI revealed the presence of numerous mass spectral peaks, some of which could be assigned to known neuropeptides, e.g., the FRF peptides (Cropper et al., 1994) and two myomodulins (Brezina et al., 1995) $\mathrm{MM}_{\mathrm{C}}$ and $\mathrm{MM}_{\mathrm{E}}$ (Fig. 1). Many additional peaks, e.g., 1387 and 1433 (masses rounded to nearest dalton for simplicity), do not correspond to any known neuropeptides and may represent novel peptides. The presence of these putative peptides in the CBCs suggests that these peptides may play a role in the generation of feeding behavior.

To examine the directionality of the peptide transport, we placed the buccal and cerebral ganglia in organ culture for $8 \mathrm{hr}$ after the CBCs were cut (Fig. $1 A$ ) and then performed MALDI on the cut ends of the CBCs. During the incubation, neuropeptides continue to be transported in the nerves ( $\mathrm{Li}$ et al., 1998) and will accumulate or deplete at the cut ends depending on the location of the neuronal somata relative to the terminals. Figure $1 B$ shows the peptide profile from both sides of the cut $\mathrm{CBC}$ after an $8 \mathrm{hr}$ delay. The results are summarized in Table 1 , in which the semiquantitative peak intensity changes at the two sides of the cut after 2 and 8 hr delays are compared. Each mass spectrum used to generate the Table was internally normalized to the intensity of $\mathrm{FRF}_{\mathrm{A}}$ peak to take into account $\mathrm{MS}$ and sample preparation differences (Garden et al., 1998). Both sides were normalized to those of control samples ( $1 \mathrm{~mm}$ section of nerve removed without incubation). Four to six replicate measurements for each section were averaged from two animals. Last, ratios of the peptide intensities from the buccal side versus those from the cerebral side are shown in the last column. A ratio of $>1$ indicates the accumulation at the buccal side, whereas a ratio $<1$ indicates the accumulation at the cerebral side. For instance, at the cerebral side of the cut, we see the accumulation of 1387 and 1433 masses (note the signal-to-noise ratio improvement at the cerebral side of 

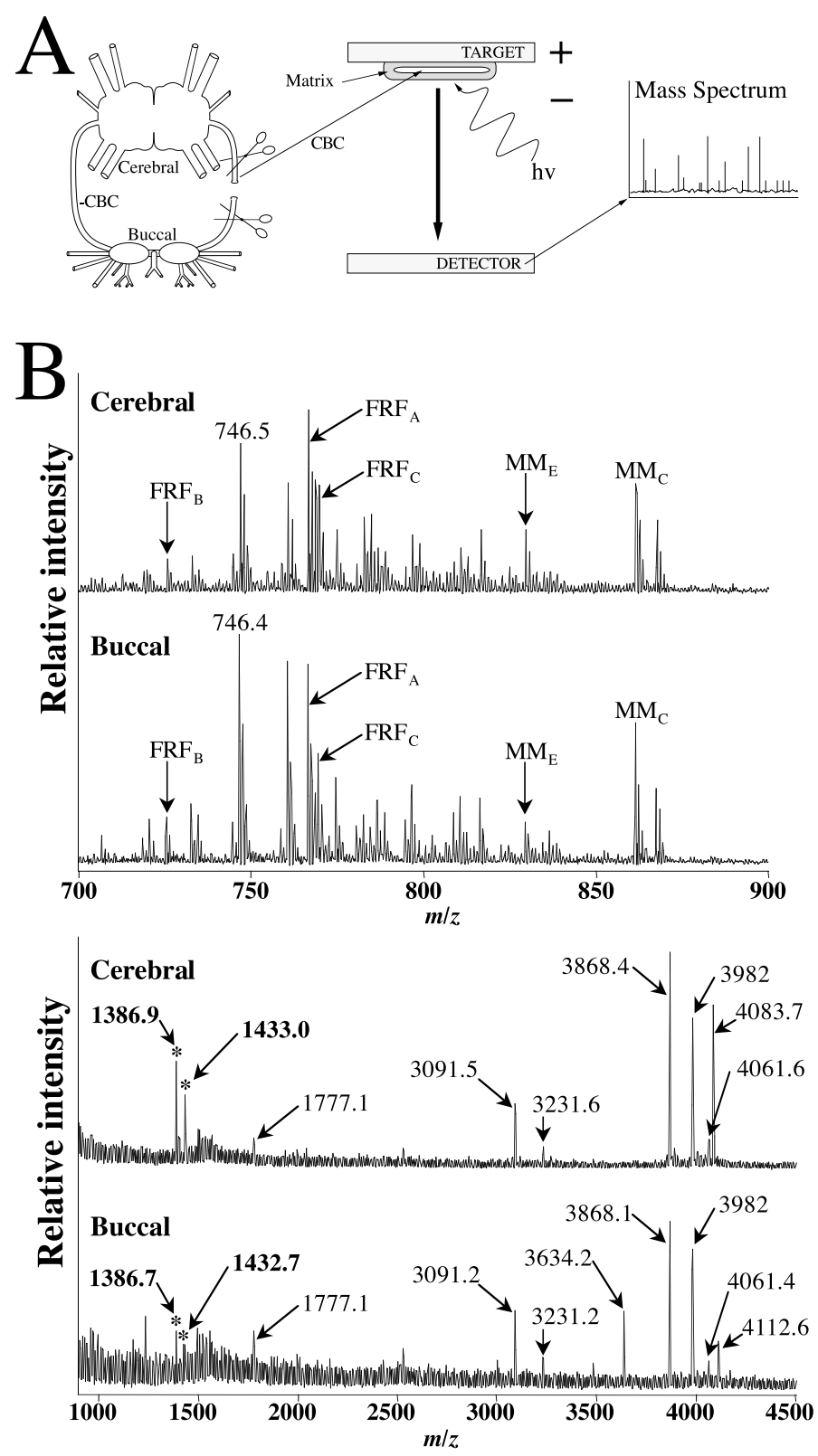

Figure 1. Neuropeptides detected in the cerebral-buccal connective using MALDI MS. $A$, Illustration of the scheme used to identify neuropeptides in the CBC. $B$, A mass spectrum obtained from cut ends of the $\mathrm{CBC}$ nerve comparing the buccal and cerebral sides. The spectrum shows several peaks that can be assigned to known neuropeptide precursors [FRFamide and Myomodulin C/E $\left.\left(M M_{C} / M M_{E}\right)\right]$ and several peaks that could not be assigned and therefore may represent novel neuropeptides. Two such peaks, 1387 and 1433 (shown in bold), were chosen for further characterization.

the cut). However, because of the heterogeneity of the nerve samples, caution should be exercised when interpreting MALDI peak heights.

\section{Sequencing FCAP using post-source decay}

In an effort to characterize the 1387 and 1433 peptides, 110 buccal ganglia were pooled, homogenized, extracted, and HPLC fractionated as described previously (Floyd et al., 1999). MALDI analyses of the resulting fractions were used to guide the purification process until the peptide of interest was collected in sufficient quantities and purity. The 1387 and 1433 peptides co-eluted, even after three stages of HPLC, suggesting that the two peptides may contain similar structures. Because MALDI-PSD sequence analysis is known to be compatible with peptide mixtures, a semipurified HPLC fraction containing both of the 1387 and 1433 peaks was subjected to PSD analysis.

Figure 2 shows the PSD fragmentation spectrum of precursor ion at $m / z$ 1387. Starting from the high mass end, using the formula $[\mathrm{M}+\mathrm{H}]^{+}-18\left(\mathrm{H}_{2} \mathrm{O}\right)-X$ (where $X=$ each of the 20 amino acid residue masses), the highest b-type ion signal is determined to be 1183.3, thus indicating that the $\mathrm{C}$-terminal residue is Trp. Because the b-type ions are generally accompanied by their corresponding a-type ions (loss of CO, yielding a 28 U lower mass ion), ions at $m / z 1183.3,1126.3,989.1,890.0,761.8$, $614.7,557.6,444.2,387.4,300.3$, and 185.2 are assigned as b-ions because of the detection of their corresponding a-ions. Using the formula $\left(m_{\mathrm{b}}+m_{\mathrm{y}}=m_{\text {precursor }}+1\right)$, paired y-ions can thus be determined as $m / z 262.3,399.4$, 498.5, 626.7, 773.8, 830.9, 888.0, 1001.1, 1088.2, and 1203.3. The amino acid sequence can then be deduced as the mass difference between consecutive b- or y-ions. On the basis of the above data, the partial amino acid sequence was determined as Xxx-Xxx-Asp-Ser-Leu/Ile-Gly-Gly-Phe-Gln/ Lys-Val-His-Gly-Trp (with Xxx being unassignable amino acid). Note that the Ile and Leu cannot be differentiated using PSD because these two amino acids are isomers; neither can Gln nor Lys be differentiated because of the similar masses. At the low mass region, several immonium ions were detected, including His (110 and $138 \mathrm{U})$, Phe (120 U), and Ile/Leu (86 U). By using the collision-induced dissociation to enhance the fragmentation in the low mass end, several additional ions are detected, including immonium ions for Ala (44 U), Gln (101, 84, $129 \mathrm{U})$, which suggests a Gln instead of a Lys present as the ninth amino acid. In addition, a weak signal at $\mathrm{m} / \mathrm{z} 72$ was observed, indicating that the first amino acid residue is Ala. Because a mass of 184 was attributed to the first two amino acid residues in the sequence, the second amino acid in the peptide is determined as a Leu/Ile residue, yielding the tentative peptide sequence as: Ala-Leu/IleAsp-Ser-Leu/Ile-Gly-Gly-Phe-Gln-Val-His-Gly-Trp. It is a little surprising that the diagnostic immonium ion corresponding to Trp (159 U) was not detected.

When the predicted peptide sequence is entered into the MSProduct database developed by the University of California San Francisco Mass Spectrometry Facility (http://prospector.ucsf. edu), possible fragment ions resulting from PSD processes are calculated by the software. Most of the fragment ions detected in the obtained PSD spectra match the predicted fragment ions, and several additional internal fragment ions are assigned, which increases the confidence of the sequence interpretation.

The PSD fragmentation pattern of the 1433 peak was similar to that of the 1387 peak, indicating a homologous peptide sequence. For example, the identical C-terminal ions (y-ions) up to $\mathrm{y}_{6}$ strongly suggest the last six amino acid residues for the 1433 peak are the same as 1387 peptide. Using the same procedure detailed earlier, the amino acid sequence predicted for the precursor ion at $m / z 1433$ is the following: $\mathrm{Xxx}(\operatorname{Trp})-\mathrm{Xxx}(\mathrm{Glu})-$ Ser-Leu/Ile-GlySer-Phe-Gln-Val-His-Gly-Trp. The assignments of the first two amino acid residues were ambiguous because of the poor quality of the fragment ion detection in the low mass region.

\section{Identification of the FCAP precursor mRNA}

The semi-nested RACE with the degenerate oligonucleotide designed to a partial amino acid sequence of the 1387 Da peptide resulted in a clone that predicted additional copies of both the 


\begin{tabular}{|c|c|c|c|c|c|c|}
\hline \multirow[b]{2}{*}{ Peptide } & \multicolumn{3}{|c|}{$2 \mathrm{hr}$ Incubation (four total samples from one animal) ${ }^{a}$} & \multicolumn{3}{|c|}{$8 \mathrm{hr}$ Incubation (six total samples from two animals) ${ }^{a}$} \\
\hline & Buccal side & Cerebral side & $\begin{array}{l}\text { Buccal/cerebral } \\
\text { ratio }\end{array}$ & Buccal side & Cerebral side & $\begin{array}{l}\text { Buccal/cerebral } \\
\text { ratio }\end{array}$ \\
\hline $\mathrm{FRF}_{\mathrm{B}}(725)$ & $133-20$ & $149-15$ & 0.89 & ND & ND & NA \\
\hline $\mathrm{FRF}_{\mathrm{A}}(766)$ & 100 & 100 & 1.00 & 100 & 100 & 1.00 \\
\hline $\mathrm{MM}_{\mathrm{E}}(829)$ & $135-65$ & $97-24$ & 1.39 & $125-25$ & $123-18$ & 1.02 \\
\hline $\mathrm{MM}_{\mathrm{C}}(861)$ & $122-16$ & $90-39$ & 1.35 & $119-41$ & $94-7$ & 1.26 \\
\hline 1387 & $75-0$ & $103-64$ & 0.73 & $75-8$ & $148-36$ & 0.51 \\
\hline 1433 & ND & $45-12$ & NA & $93-18$ & $115-28$ & 0.81 \\
\hline 2527 & $116-36$ & $94-42$ & 1.23 & $92-27$ & $74-32$ & 1.24 \\
\hline 3090 & $122-52$ & $141-48$ & 0.86 & $113-49$ & $140-13$ & 0.81 \\
\hline 3230 & $177-56$ & $152-50$ & 1.16 & $190-57$ & $147-47$ & 1.29 \\
\hline 3867 & $60-12$ & $62-18$ & 0.97 & $110-44$ & $153-37$ & 0.72 \\
\hline 3982 & $73-22$ & $72-22$ & 1.01 & $108-36$ & $121-19$ & 0.89 \\
\hline 4082 & ND & ND & NA & $92-42$ & $117-27$ & 0.79 \\
\hline 4620 & $178-49$ & $470-284$ & 0.38 & ND & $206-128$ & NA \\
\hline $\mathrm{ACa}(5022)$ & $173-66$ & $87-18$ & 1.99 & $107-37$ & $128-73$ & 0.83 \\
\hline
\end{tabular}

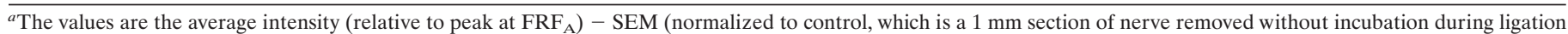
experiment). ND, Not detected; NA, not applicable.

1387 and 1433 peptides. This insert used cDNA libraries to define the full coding sequence of the precursor to these peptides (GenBank accession number AY118084). The predicted mRNA contained a $2226 \mathrm{bp}$ open reading frame that encodes a 742 amino acid precursor shown in Figure $3 A$. The precursor had a predicted signal peptide and a predicted cleavage site between Cys(22) and Lys(23) (Nielsen et al., 1997), indicating that the protein is targeted to the secretory pathway. Analysis of the precursor structure indicates that, on the basis of the location of potential furin-like consensus cleavage sites (Seidah and Chretien, 1999), it predicts a total of 25 copies of eight different structurally related peptides. The eight unique peptides were named FCAPa through FCAPh on the basis of the order of first appearance on the precursor as shown in Table 2. The organization of the FCAPs on the precursor is illustrated in Figure $3 B$. Most of these FCAPs are present in single copies on the precursor. The two peptides that are present in multiple copies on the precursor, FCAPb and FCAPg, have predicted masses that correspond to the 1387 $(\mathrm{FCAPb})$ and 1433 (FCAPg) peaks that were detected in the CBCs and sequenced with PSD. In addition to the FCAPs, the precursor predicts numerous linker or connecting peptides, most of which are short and acidic in nature.

\section{Processing of the FCAP precursor protein}

The synthesis of FCAPb and FCAPg has been confirmed on the basis of the detection of corresponding mass spectral peaks in the CBCs and PSD sequencing of these peptides from buccal extracts. We used mass spectral analysis of FCAP-containing neurons to examine the presence of the additional predicted FCAPs and connecting peptides, thereby further defining the processing of the FCAP precursor. We chose the F-cluster bottom layer $(\mathrm{CFb})$ neurons for this analysis because they were easily identifiable, expressed the FCAPs (see below), and exhibited MALDI peaks at 1387 and 1433 in previous studies (Rubakhin et al., 1999). As shown in Figure 4, all eight of the FCAP peptides predicted by the FCAP precursor were detected by MALDI, thus confirming their synthesis. Unlike the other FCAPs, FCAPe N terminus results from processing at a monobasic site $\left(\mathrm{Arg}^{221}\right)$. Longer, N-terminally extended versions of FCAPe (i.e., without cleavage at $\mathrm{Arg}^{221}$ ) were not detected. Not surprisingly, the two most intense mass spectral peaks correspond to FCAPb (1387) and FCAPg (1433), the two FCAPs with multiple copies encoded by the precursor. In addition, peaks corresponding to two connecting peptides, Gly ${ }^{117}$-Asp ${ }^{131}$ and $\mathrm{Thr}^{713}-\mathrm{Val}^{728}$, were observed in the MALDI spectra of cerebral F-cluster cells. Table 2 lists the mass measurement accuracy for the detection of the FCAPs and two connecting peptides. Because many of the linker peptides are small (five to six amino acids in length with a mass range of 400-700 Da), the low mass gate (800 Da) used to eliminate the interference from matrix and phospholipid peaks prevented the detection of these short, linker peptides. Thus, we cannot exclude the possibility that additional connecting peptides derived from the FCAP precursor are produced and may possess bioactivity.

\section{Distribution of FCAPs in the CNS and peripheral tissues}

The overall distribution of the FCAP mRNA was determined using Northern blot analysis on total RNA obtained from specific ganglia of five animals. Northern analysis (Fig. 5) shows that FCAP mRNA is $\sim 5.5 \mathrm{~kb}$ in length. The relative abundance of FCAP mRNA in the CNS is pleural $\approx$ pedal $>>$ abdominal $\approx$ buccal $\approx$ cerebral ganglia. A more detailed analysis of FCAP distribution in the CNS and gut of Aplysia was conducted using a combination of ISH and IMM. Correlation of IMM and ISH staining was used to assess the specificity of these two methods (Eberwine et al., 1994). The distribution of FCAP-positive neurons (see below) was similar using both methods, indicating that staining is specific (Eberwine et al., 1994). Furthermore, the overall distribution of FCAP observed with IMM and ISH staining was consistent with the distribution observed with Northern analysis. For example, Northern analysis (Fig. 5) shows that the level of FCAP mRNA is highest in the pleural and pedal ganglia, and the concentration of FCAP-positive neurons observed with IMM and ISH is also highest in these ganglia (Figs. 6, 7, 8).

ISH and IMM staining were performed on separate preparations from both small (10-15 gm) and large (200-400 gm) Aplysia. Some variability was observed in the size and number of 
A

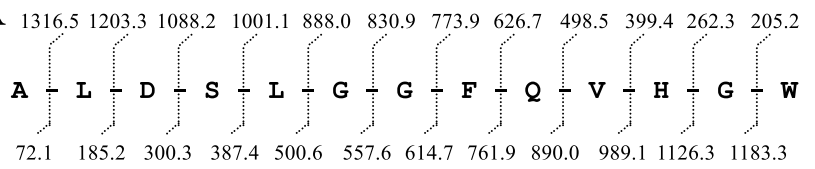

B

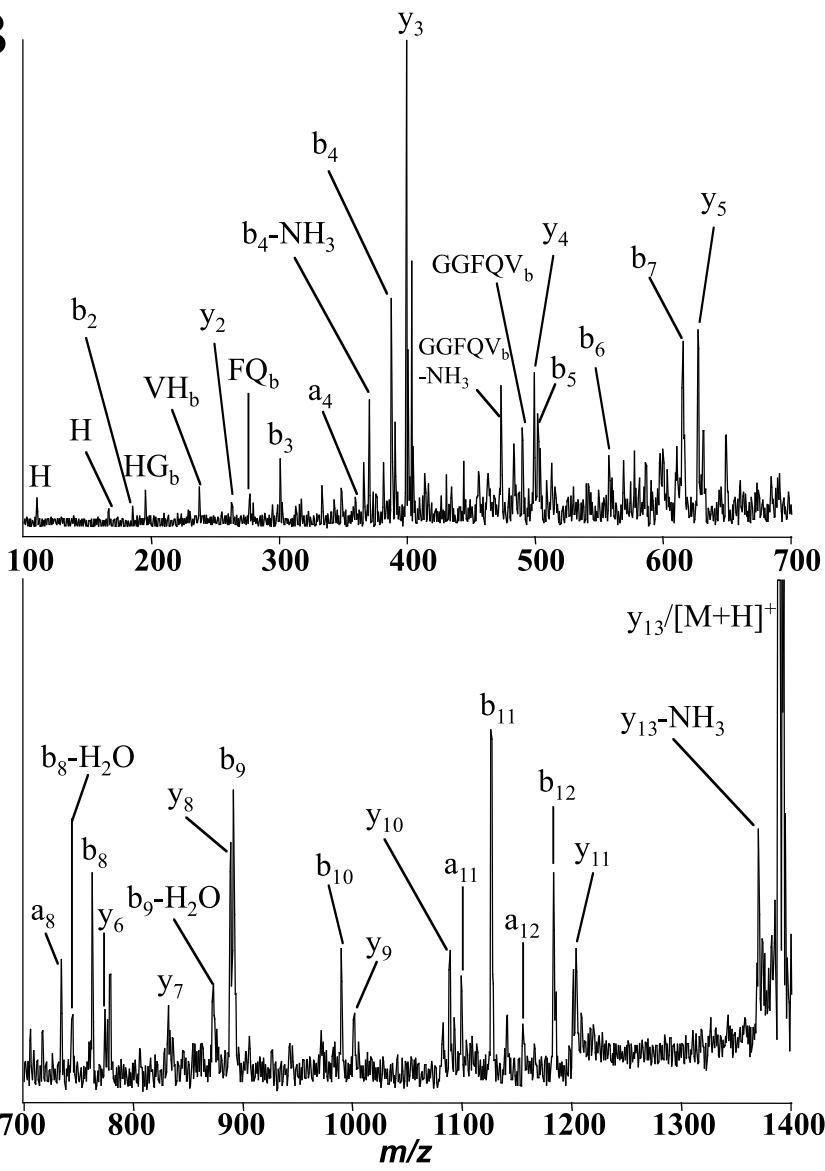

A

MTFAASFRALLCVLFCAALVHCKTRTKRYVPHSELWRILAVVDELQREQA 50

AEQRQEDALALALRSDIAGGGGGGQLADNVRWFPETYDYGALADRDVDKR 100

VFDSLGGYEVHGFKKRGSLDAIPODTDASSDKRALDSLGGFQVHGWKRAL 150

DTLGGFQVHGWKRGSGAEKRQVDRLGGFQVHGWKKRALDSLGGFQVHGWK 200

KRGTGGQMHASSPRVVPWGSRSLLADTQSGHRWKRDTELVENRQTTGQQT 250

EVNKRALDSLGGFQVHGWKRSGEAGKRQVDSLGGFQVHGWKRADDQGKRA 300

LDSLGGFQVHGWKRFDNSAGEKRALDSLGGFQVHGWKRAGDKKSLDSLGS 350

FQVHGWKRFDNDISGQKRSLDSLGSFQVHGWKRSDQDNKRALDSLGGFQV 400

HGWKRADDDGKRSLDSLGSFQVHGWKRADEDDKKSLDSLGSFQVHGWKRG 450

DEDDKRSLDSLGSFQVHGWKRADEDDKRSLDSLGSFQVHGWKRSDEDDKR 500

SLDSLGSFQVHGWKRSDEDDKRSLDSLGSFQVHGWKRADEDDKRSLDSLG 550

SFQVHGWKRNSPGLKRALDSLGGFQVHGWKRNNEYYSGAENEKRALDSLG 600

GFQVHGWKRDQPGEKRSLDSLGSFQVHGWKRNLNNLGSFQVHGWKKNSAD 650

EMGDKPGVESYQDNSGKILSGKAQEFEGGDETGDIHGVVRTLSGVDASGK 700

ERENIKELDAKF KTNDGGVGVEHIFVDNVKSADDDVPSAGQM *

742

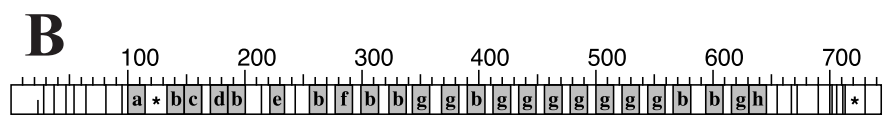

Figure 3. Structure of the FCAP precursor. A, Amino acid sequence of the FCAP precursor predicted by the open reading frame of the consensus cDNA sequence with amino acids numbered at right. Some of the potential monobasic, dibasic, and tribasic processing sites are shown in bold, and the predicted signal sequence cleavage site (VHc-kT) is shown in lowercase. The precursor predicts numerous copies of FCAPs and peptides with similar sequence (shown underlined). In addition, the precursor predicts numerous connecting peptides that have sequences unrelated to FCAPs and are often short and acidic. Two of these peptides that were detected with MALDI (see Fig. 4) are shown with dotted underline. B, Schematic diagram showing the organization of the FCAP precursor protein. Amino acids are numbered at the top, cleavage sites are shown as vertical lines, and the FCAPs are shown in gray. Mass spectral peaks corresponding to all the FCAPs (gray) and two connecting peptides (asterisks) were detected by MALDI-TOF MS (see Fig. 4).

ganglion. A few additional FCAP-positive neurons were observed in both pleural ganglia. The pleural sensory neurons were also observed to be weakly FCAP positive. In the pedal ganglion, a major cluster of FCAP-positive cells was observed on the dorsal surface near the pleural-pedal connective. Another major cluster of FCAP-positive neurons was observed near the lateral edge of the dorsal pedal ganglion. On the ventral surface, an intensely staining cluster of FCAP-positive neurons was also observed near the pedal-pedal commissure. This cluster was located on the edge of the ganglion and could be observed from both the dorsal and ventral surfaces but was more prominent on the ventral surface. A few small FCAP-positive neurons were also observed on the central ventral surface of the pedal ganglion. In the dorsal abdominal ganglion, an intensely staining FCAP-positive neuron was observed in the ventral upper quadrant of the left hemiganglion, and a cluster of neurons was observed in the right hemiganglion. Several smaller neurons located on the ventral abdominal ganglion also were positive for FCAP. A weakly staining band of FCAP-positive neurons was observed medially on both the dorsal and ventral posterior edge, and one weakly staining neuron was seen on the lateral posterior edge of the abdominal ganglion. The bag cells were also observed to be FCAP positive.

Pleural, pedal, and abdominal ganglia (Fig. 6)
An intensely staining FCAP-positive cluster of small neurons was observed in the right pleural ganglion but not in the left pleural 


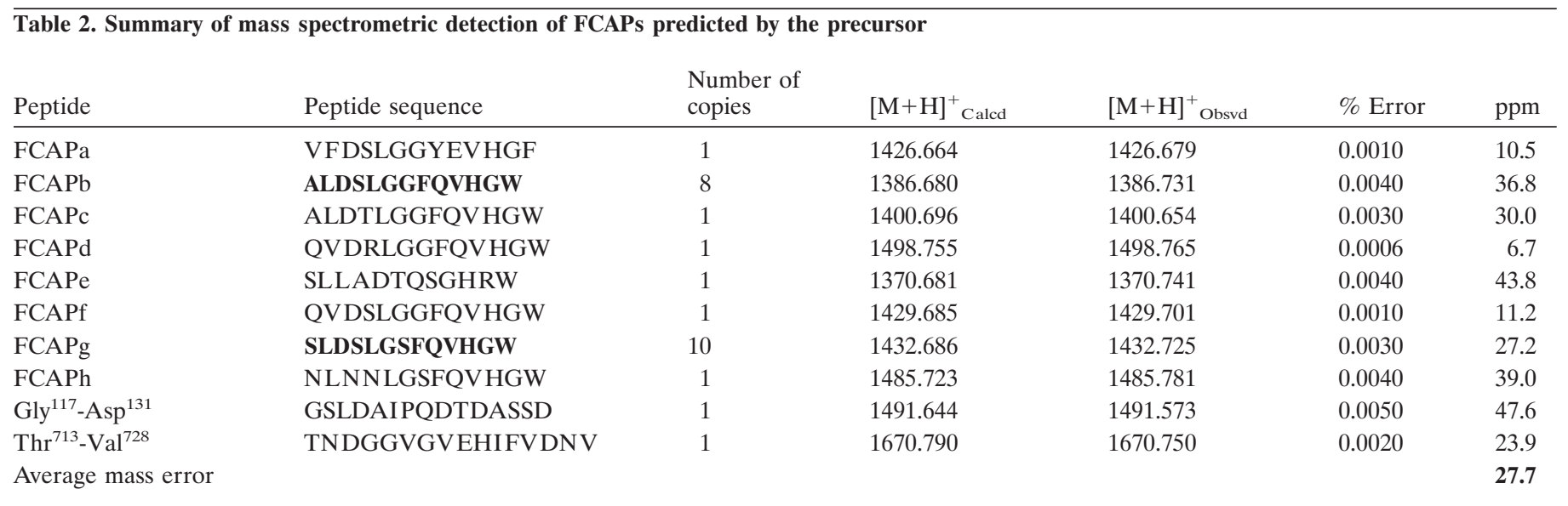

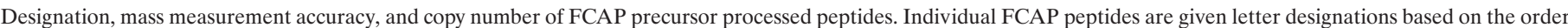

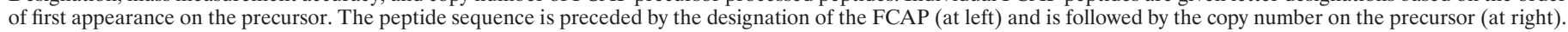
Peptide sequences in bold indicate multiple copies encoded by the precursor.

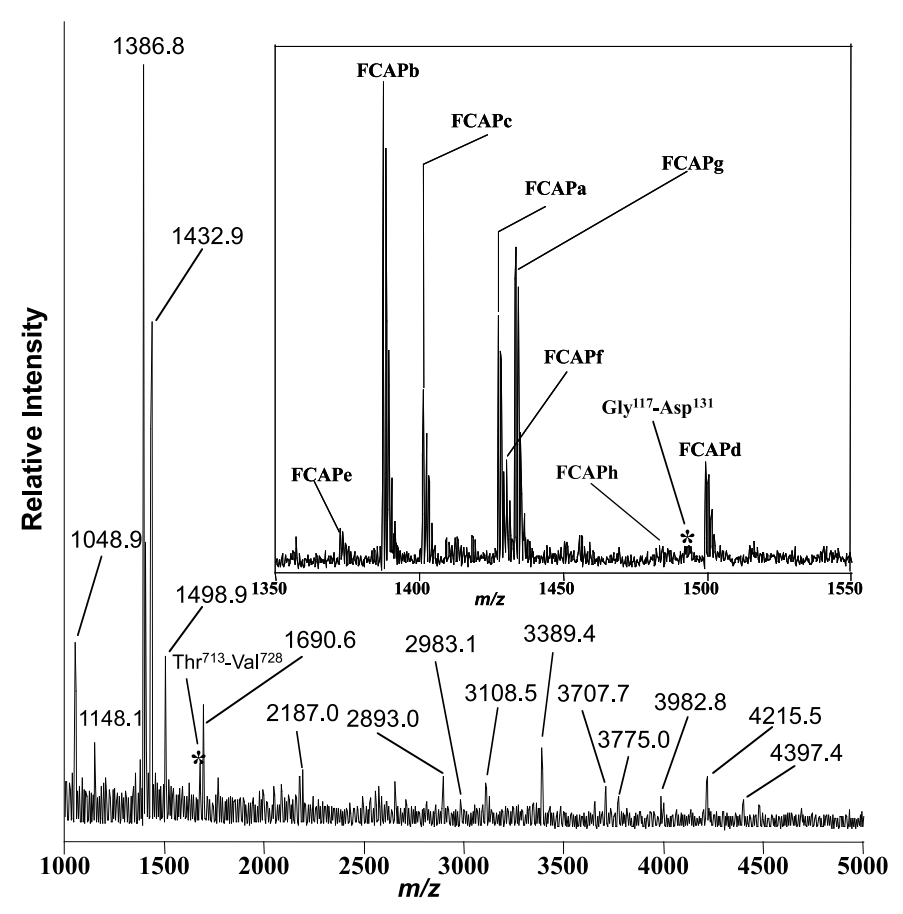

Figure 4. MALDI-TOF MS spectrum of a cerebral F-cluster bottomlayer neuron $(\mathrm{CFb})$. In addition to FCAPb and FCAPg, which were detected originally in the $\mathrm{CBC}$, the predicted peptides derived from the FCAP precursor, FCAPa, FCAPc, FCAPd, FCAPe, FCAPf, and FCAPh, were detected in these neurons. In addition to the FCAPs, two connecting peptides were detected in this neuron.

\section{Cerebral ganglion (Fig. 7)}

The dorsal and ventral surfaces of the cerebral ganglia contained a comparable number of FCAP-positive neurons. On the dorsal surface, a group of nonsuperficial small neurons in the F-cluster and B-cluster were observed to be FCAP positive [nomenclature of clusters according to Jahan-Parwar and Fredman (1976) and Phares and Lloyd (1996)]. An additional group of larger FCAPpositive neurons were observed in the C-cluster. A few FCAPpositive neurons were present in the E-cluster and in the area in which optic nerves enter the cerebral ganglion. A cluster of smaller FCAP-positive neurons was also observed in the D-cluster. On the ventral surface, FCAP-positive neurons were

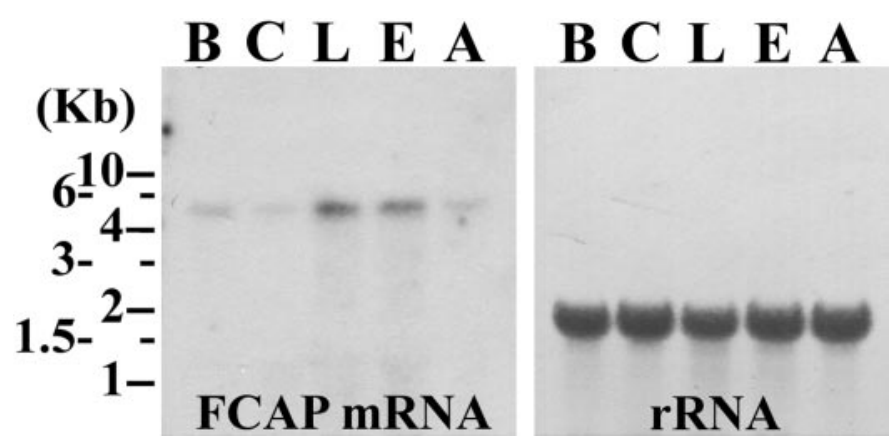

Figure 5. Northern analysis of FCAP precursor mRNA in different ganglia of Aplysia. Left panel (FCAP $m R N A$ ) shows hybridization of random primed FCAP precursor cDNA to total RNA (10 $\mu \mathrm{g}$ per lane) isolated from buccal $(B)$, cerebral $(C)$, pleural $(L)$, pedal $(E)$, and abdominal $(A)$ ganglia. Positions and size (in kilobases) of the RNA markers are noted on the left. The right panel ( $r R N A)$ shows methylene blue-stained ribosomal RNA from the same blot, demonstrating that an equal amount of RNA was loaded in each lane.

observed in the M-cluster, the E-cluster, and the G-cluster. In addition, a weakly stained cluster of small neurons was observed near the cerebral-pleural connective. Intense FCAP immunostaining was observed in the neuropile of the cerebral ganglion, including the E-cluster. FCAP-immunopositive axons were observed in all the nerves emanating from the cerebral ganglion, including the CBC. Particularly intense FCAP immunostaining was observed in the rhinophore nerve.

\section{Buccal ganglion (Fig. 8)}

Both immunostaining and ISH staining revealed the presence of three bilaterally symmetrical pairs of FCAP-positive neurons. Two pairs of FCAP-positive neurons were located on the rostral surface, and one pair was located on the caudal surface. In addition to the bilaterally symmetrical FCAP-positive neurons, both ISH and IMM revealed the presence of an asymmetrical neuron. This neuron is located on the lateral caudal surface of the left buccal hemiganglion. All of the FCAP-positive neurons were of similar size $(80-100 \mu \mathrm{m})$ in adult animals, located in a region that extended from the central part of the rostral surface toward the dorsal edge of this surface. The medial pair of FCAP-positive neurons on the rostral surface of the ganglion appeared to share several characteristics (position, size, and morphology) with neu- 


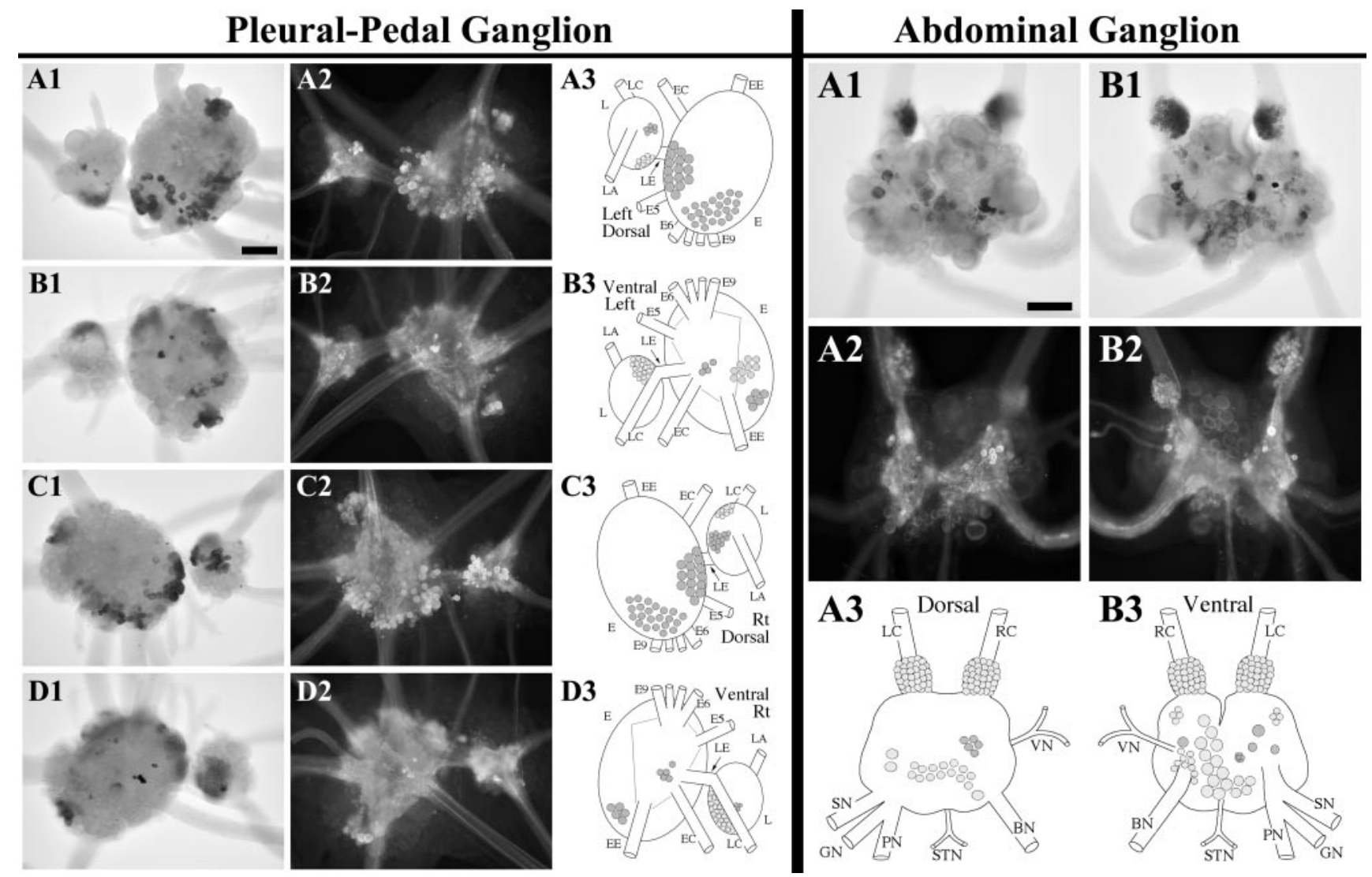

Figure 6. FCAP in the pleural, pedal, and abdominal ganglia. Pleural-Pedal Ganglion: A1, In situ hybridization of left ganglion pair dorsal surface. A2, Immunocytochemistry of the left ganglion pair dorsal surface. $A 3$, Drawing of the FCAP neurons on the dorsal surface of the left ganglion pair. $B 1$, In situ hybridization of left ganglion pair ventral surface. B2, Immunocytochemistry of the left ganglion pair ventral surface. B3, Drawing of the FCAP neurons on the ventral surface of the left ganglion pair. C1, In situ hybridization of right ganglion pair dorsal surface. C2, Immunocytochemistry of the right ganglion pair dorsal surface. C3, Drawing of the FCAP neurons on the dorsal surface of the right ganglion pair. D1, In situ hybridization of right ganglion pair ventral surface. D2, Immunocytochemistry of the right ganglion pair ventral surface. D3, Drawing of the FCAP neurons on the ventral surface of the right ganglion pair. $L$, Pleural ganglion; $E$, pedal ganglion; $L E$, pleuropedal connective; $E E$, pedal commissure; $E C$, cerebropedal connective; $L C$, cerebropleural connective; $L A$, pleuroabdominal connective; E5, posterior tegumentary nerve (P5); E6, anterior parapodial nerve (P6); E9, posterior pedal nerve (P9). Not all nerves are drawn for simplicity. Abdominal Ganglion: A1, In situ hybridization of dorsal surface. A2, Immunocytochemistry of dorsal surface. $A 3$, Drawing of the FCAP neurons on the dorsal abdominal ganglion. $B 1$, In situ hybridization of ventral surface. $B 2$, Immunocytochemistry of ventral surface. B3, Drawing of the FCAP neurons on the ventral abdominal ganglion. LC, Left pleuroabdominal connective; $R C$, right pleuroabdominal connective; $V N$, vulvar nerve; $B N$, branchial nerve; $S T N$, spermathecal nerve; $P N$, pericardial nerve; $G N$, genital nerve; $S N$, siphon nerve. Neurons drawn in darker shades of gray stain more intensely. Scale bars, $300 \mu \mathrm{m}$.

ron B21 (Rosen et al., 2000). B21 contains SCP (Miller et al., 1994), and after costaining with rabbit anti-SCP and rat antiFCAP antibodies, we found that the medial pair of FCAPpositive neurons was also SCP positive (Fig. 9A1,A2). To conclusively demonstrate that B21 is FCAP positive, we injected identified B21s with carboxyfluorescein, immunostained with FCAP, and found that B21s were FCAP positive (Fig. 9B1,B2). In some preparations of adult animals (Fig. 9B1), a third pair of FCAP-positive neurons were observed with both IMM and ISH in the rostral buccal ganglion, directly below the B21s. These neurons are likely to be the B22s, which are neurons that have many characteristics similar to the B21s.

\section{Other structures}

In addition to visualizing neuronal somata, IMM also revealed intense FCAP staining of the buccal neuropile. Furthermore, FCAP-immunostained axons were observed in all of the nerves, including the CBCs, emanating from the buccal ganglia. The most intense staining of axons was observed in the esophageal nerves. Because it is unlikely that the FCAP-positive neurons of the buccal ganglion could give rise to all the immunostained axons in the esophageal nerve, we sought to determine whether the FCAP-positive axons observed in the esophageal nerve could originate in neurons of the gut (Kandel, 1979; Fujisawa et al., 1999; Furukawa et al., 2001). When we immunostained the esophagus and gut of $10 \mathrm{gm}$ animals, we observed both neurons and processes that were FCAP immunopositive (Fig. 10). FCAPimmunopositive processes were found in the esophagus (Fig. $10 A$ ), crop (Fig. 10B,C), stomatogastric ring (Fig. 10C), triturating stomach (Fig. 10C), and filter chamber (Fig. 10D). FCAPpositive somata were present in the stomatogastric ring (Fig. 10C) and filter chamber (Fig. 10D). Thus, some of the FCAP-positive axons in the esophageal nerve may originate in the FCAPimmunopositive neurons of the gut.

CBCs

To further characterize the origin of FCAPs in the CBCs, we immunostained the cut connectives. Consistent with the MALDI results, FCAP-immunopositive axons were observed in cut CBCs of both the cerebral and buccal ganglia. Also consistent with 


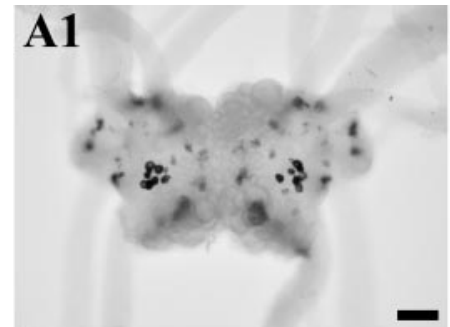

\section{B1}
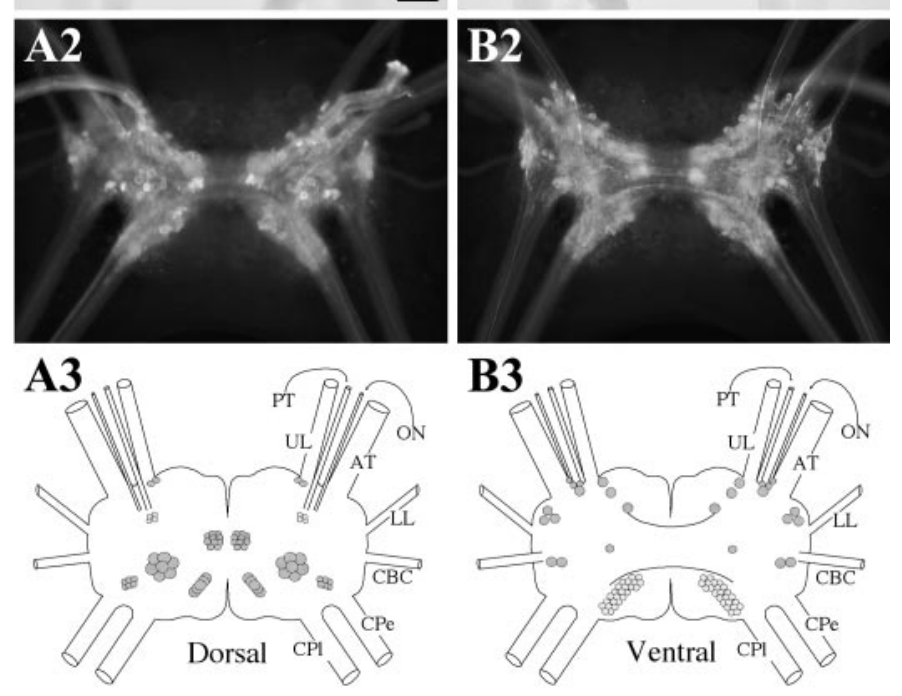

Figure 7. FCAP in the cerebral ganglion. A1, In situ hybridization of the dorsal surface. $A 2$, Immunocytochemistry of dorsal surface. $A 3$, Drawing of the FCAP neurons on the dorsal cerebral ganglion. B1, In situ hybridization of ventral surface. B2, Immunocytochemistry of ventral surface. $B 3$, Drawing of the FCAP neurons on the ventral cerebral ganglion. $U L$, Upper labial nerve; $P T$, posterior tentacular nerve; $O N$, optic nerve; $A T$, anterior tentacular nerve; $L L$, lower labial nerve; $C B C$, cerebrobuccal connective; $\mathrm{Cpe}$, cerebropedal connective; $\mathrm{CPl}$, cerebropleural connective. Neurons drawn in darker shades of gray stain more intensely. Scale bar (shown in $A 1$ for $A 1-B 3$ ): $200 \mu \mathrm{m}$.

MALDI results, FCAP immunostaining of accumulated material was more intense at the cut end of the $\mathrm{CBC}$ that was still attached to the cerebral ganglion (Fig. 11 $A$ ) than the cut end of the $\mathrm{CBC}$ that was still attached to the buccal ganglion (Fig. 11B). Accumulation of FCAP-immunopositive material was particularly apparent at the tip of the cut CBC that was still attached to the cerebral ganglion. Thus, both MALDI and immunostaining suggest that more FCAP originates on the cerebral side of the CBC than on the buccal side. To determine whether any of the FCAPimmunopositive axons of the $\mathrm{CBC}$ originate in neurons of the cerebral and buccal ganglia, we combined backfills of the $\mathrm{CBC}$ with FCAP immunostaining. Biocytin backfills of the CBC were visualized with fluorescein-labeled streptavidin, and FCAP was visualized with rhodamine-red-labeled secondary antibodies. We observed that four of the CBC backfilled neurons (Fig. 11C1) were FCAP immunopositive (Fig. 11C2) in the cerebral ganglion, three of these neurons were located in the M-cluster, and one was located adjacent to the metacerebral cell (MCC). Concordance of these results with ISH suggests that the FCAP-immunopositive CBC-backfilled neurons of the cerebral ganglion are indeed FCAP positive. In the rostral buccal ganglion, only one of the backfilled neurons (Fig. 11D1) was FCAP immunopositive (Fig. 11D2). Thus the lateral pair of FCAP-positive neurons observed by both IMM and ISH in the rostral buccal ganglion (see above) are BCIs. Although, we determined that there are both buccal
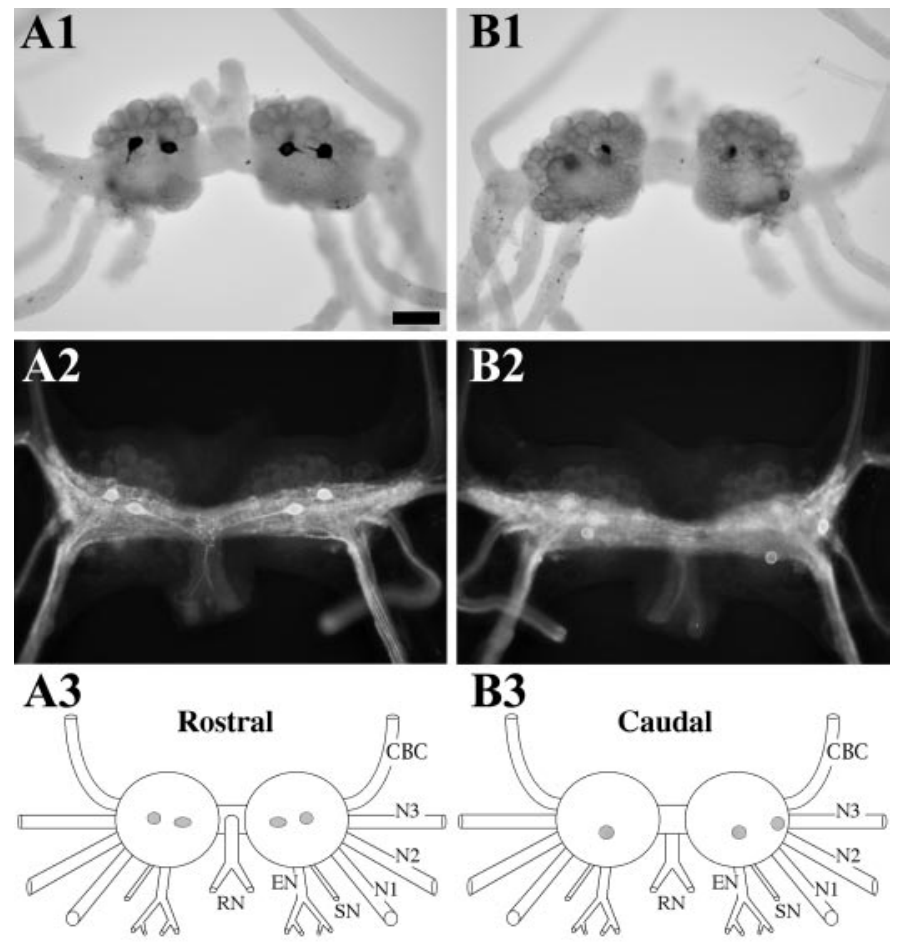

Figure 8. FCAP in the buccal ganglion. A1, In situ hybridization of the rostral surface. $A 2$, Immunocytochemistry of rostral surface. Immunoreactive axons are present in the CBC. $A 3$, Drawing of the FCAP-positive neurons on the rostral surface of buccal ganglia. B1, In situ hybridization of caudal surface. B2, Immunocytochemistry of caudal surface. B3, Drawing of the FCAP-positive neurons on the caudal surface of buccal ganglia. $C B C$, Cerebrobuccal connective; $N 1$, nerve 1 (B4); N2, nerve 2 (B5); N3, nerve 3 (B6); $S N$, salivary nerve (B3); $E N$, esophageal nerve (B2); $R N$, radula nerve (B1). Neurons drawn in darker shades of gray stain more intensely. Scale bar (shown in $A 1$ for $A 1-B 3$ ): $200 \mu \mathrm{m}$.

and cerebral ganglion neurons that project to the CBCs, we cannot exclude the possibility that some of the FCAPs detected in the CBCs originate outside these ganglia. Other such sources could also contribute to observed signal asymmetries between the cut ends of the CBCs.

\section{Physiological action of FCAPs}

Physiological actions of FCAP were examined in preparations in which feeding motor programs were elicited by stimulation of the command-like neuron, CBI-2 (Rosen et al., 1991). Single twophase cycles of motor programs consisting of protraction and retraction phases were induced every $2 \mathrm{~min}$ by stimulating CBI-2 at $8-10 \mathrm{~Hz}$ with $10 \mathrm{msec}$ current pulses. Electrical activity in nerve $\mathrm{I} 2$ was used to monitor protraction because this nerve contains axons of protraction phase motor neurons B31/32 and B61/62 (Hurwitz et al., 1996). Sustained depolarization in B4/5 was used to monitor retraction (Church and Lloyd, 1994; Jing and Weiss, 2001). Radula closure motor neuron B8 or electrical activity in the radula nerve $(\mathrm{RN})$, which contains the axon of $\mathrm{B} 8$, was used to monitor radula closure activity (Morton and Chiel, 1993b). We found that FCAPb had no appreciable effect on the parametric features of the CBI-2-elicited motor programs (data not shown). At $10^{-5} \mathrm{M}$, in eight of nine preparations, FCAP induced frequent motor programs that cycled for minutes until washout of the peptide (Fig. 12A). CBI-2 did not fire during these FCAP-induced programs. In six of the eight preparations, the motor programs were regular; i.e., the intercycle interval was 

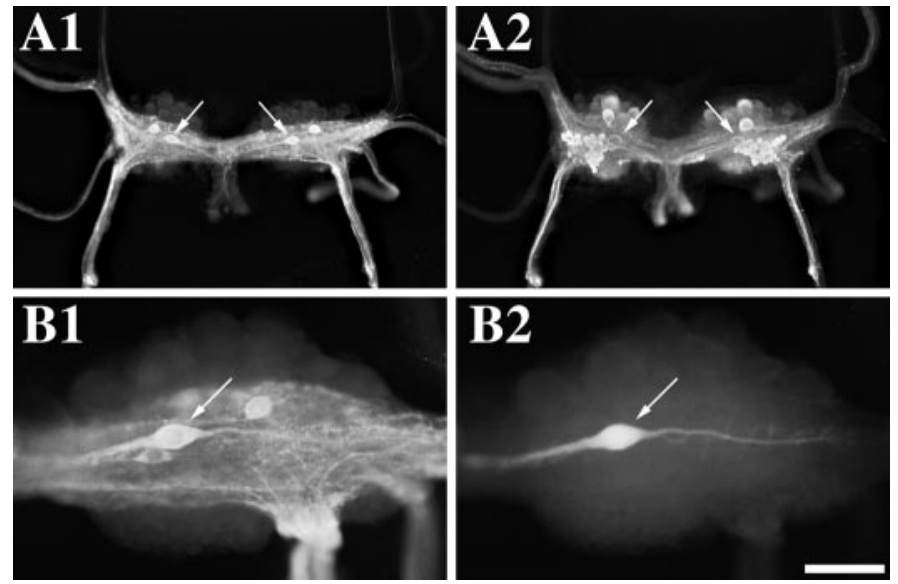

Figure 9. FCAP in the radula mechanoafferent sensory neuron B21 of the buccal ganglion. A, Buccal ganglion from a juvenile Aplysia (10 gm) double labeled with rat antibody to FCAP (rhodamine red; $A 1$ ) and rabbit antibody to SCP (fluorescein; $A 2$ ). $B$, Buccal hemiganglion from an adult Aplysia (200 gm) immunostained with FCAP (B1) in which B21 (arrows) was electrophysiologically identified and injected with carboxyfluorescein (B2). The medial bilaterally symmetric pair of FCAP-positive neurons on the rostral surface of the buccal ganglion are B21s. Notice that a third neuron in the rostral buccal hemiganglion of this adult animal (just below B21) is also FCAP immunopositive. This neuron is likely to be B22, the sister neuron of B21. Scale bar (shown in B2): $A, 500 \mu \mathrm{m} ; B, 250 \mu \mathrm{m}$.
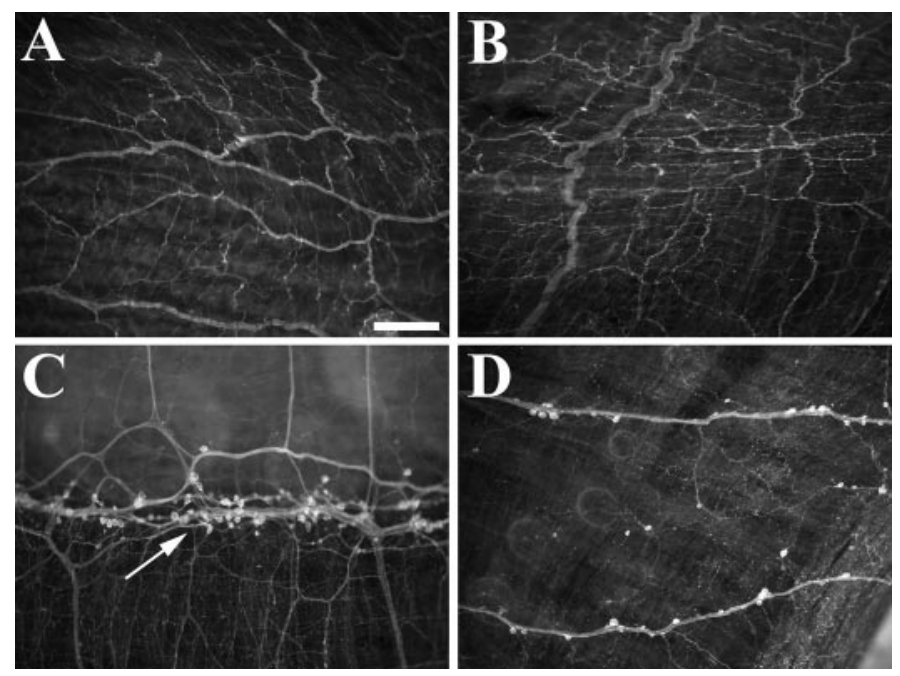

Figure 10. FCAP in the digestive tract. $A$, Esophagus immunostaining. $B$, Crop immunostaining. $C$, Stomatogastric ring (arrow) immunostaining. The crop is below and triturating stomach is above the arrow. $D$, Filter chamber immunostaining. Notice FCAP-immunoreactive processes are present throughout the gut, and FCAP-immunopositive neurons are apparent in the stomatogastric ring and filter chamber. All panels are from 10-15 gm Aplysia. Scale bar (shown in $A$ for $A-D$ ): $250 \mu \mathrm{m}$.

brief, whereas in the other two preparations, the intercycle interval was long and variable. To examine whether the motor programs elicited by FCAPb were dependent on the occasional test stimulation of CBI-2, we did some of these experiments without stimulation of CBI-2 and found no differences. The patterns of FCAP-elicited motor programs were similar to those elicited by stimulation of CBI-2 (Fig. 12B,C). On the basis of the activity in the radula nerve or activity of $\mathrm{B} 8$ during protraction and retraction (Morton and Chiel, 1993a,b; Church and Lloyd, 1994; Nargeot et al., 1999; Jing and Weiss, 2001; Morgan et al., 2002), the
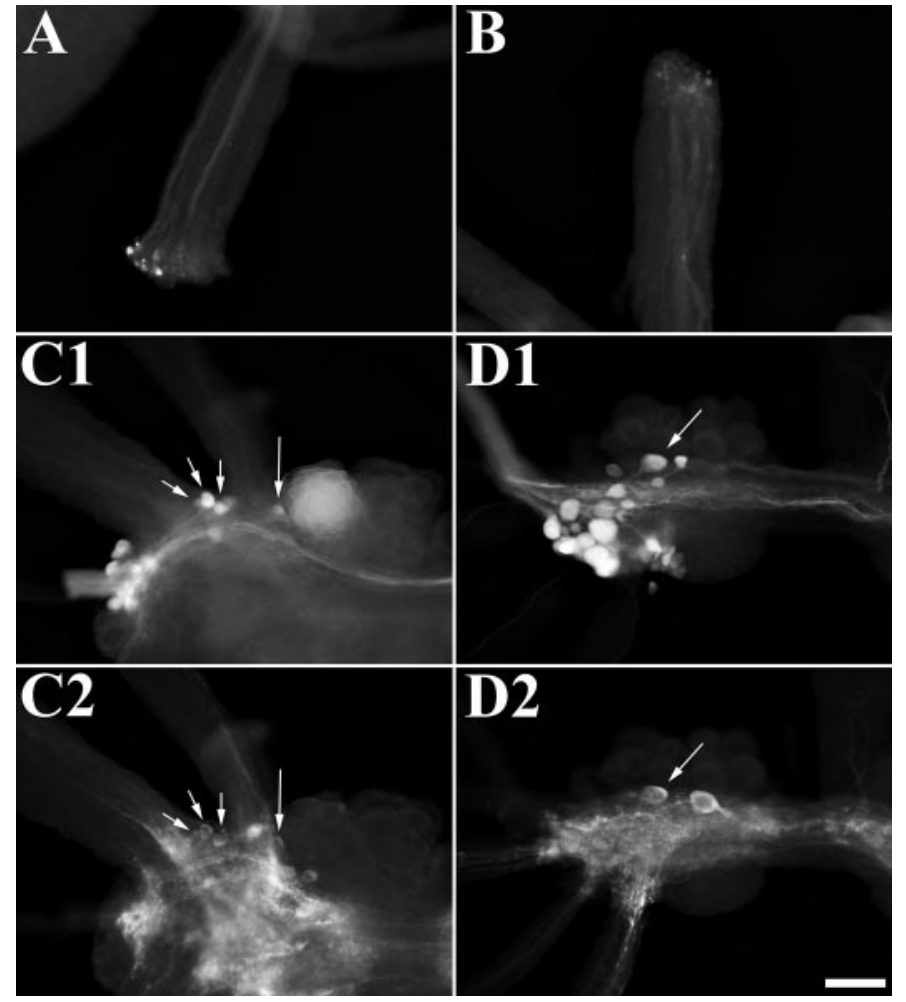

Figure 11. FCAP immunostaining in backfills of the CBC. A, A cut CBC attached to the cerebral ganglion (top) shows accumulation of FCAP immunoreactivity at the cut end of the nerve (bottom). B, A cut CBC attached to the buccal ganglion (bottom) shows some accumulation of FCAP immunoreactivity at the cut end of the nerve (top). FCAP accumulation at the $\mathrm{CBC}$ cut end appears more intense on the cerebral side than the buccal side. $C 1, \mathrm{CBC}$ backfill of the cerebral ganglion (anterior ventral surface) shows several backfilled neurons. $C 2$, FCAP immunostaining of the same field as in $\mathrm{C} 1$ shows that four of the backfilled neurons are FCAP immunopositive (arrows). Three of the FCAP-positive backfilled neurons are in the M-cluster, and one is adjacent to the MCC. D1, CBC backfill of the buccal ganglion (rostral surface of the ipsilateral hemiganglion) shows a number of backfilled neurons. D2, FCAP immunostaining of the same field as in D1 shows that one of the backfilled neurons is FCAP immunopositive (arrow). The lateral bilaterally symmetric pair of FCAP-positive neurons on the rostral surface of the buccal ganglion are BCIs. Scale bar (shown in D2): $A, B, 100 \mu \mathrm{m} ; C, D, 200 \mu \mathrm{m}$.

motor programs elicited by FCAPb were ingestive (i.e., B8 fired most strongly during retraction phase) in a majority of preparations (Fig. 12A,B) $(n=6$ of 8$)$. In the other two cases, the motor programs were either egestive (i.e., B8 fired mostly during protraction phase) or intermediate (i.e., B8 fired in both protraction and retraction) (Morgan et al., 2002).

We also tested the effect of FCAPg and found that it can also induce multicycle motor programs; however, it is less potent than $\mathrm{FCAPb}$. At the same concentration of $10^{-5} \mathrm{M}$, the motor programs elicited by FCAPg have longer intercycle intervals $(n=3)$. To compare FCAPb and FCAPg in two of these experiments, FCAPb was also applied either after FCAPg or before FCAPg; $\mathrm{FCAPb}$-elicited motor programs cycled faster than those elicited by FCAPg.

\section{DISCUSSION}

Neuropeptides have been shown to be regulators of a number of behaviors, including feeding in many different species, both vertebrate and invertebrate (Woods et al., 1998; Elmquist et al., 1999; Strand, 1999). Because of several technical advantages of 


\section{A1. Control}

$\mathrm{CBI}-2$

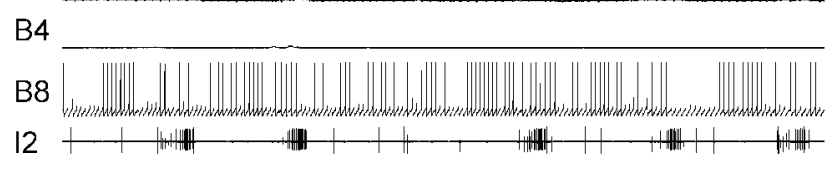

$\mathrm{RN}$

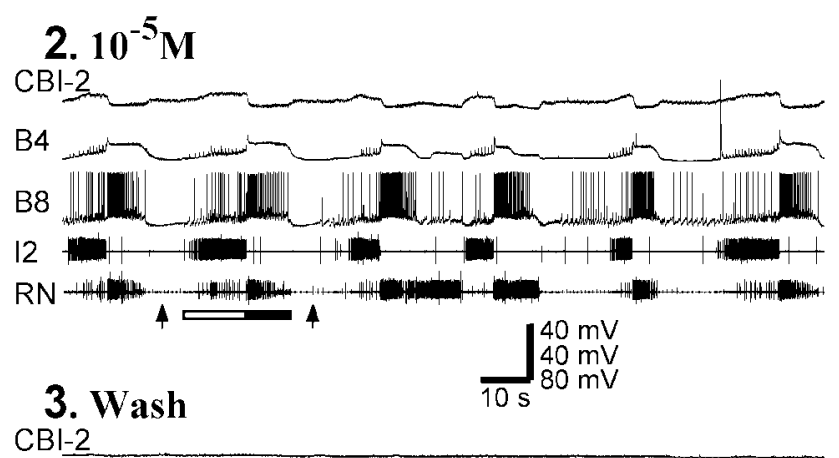

B4

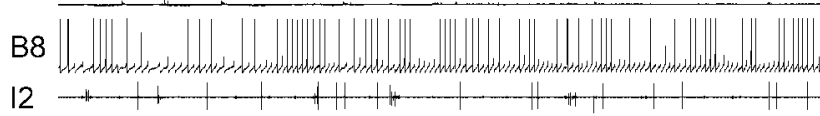

$\mathrm{RN}$
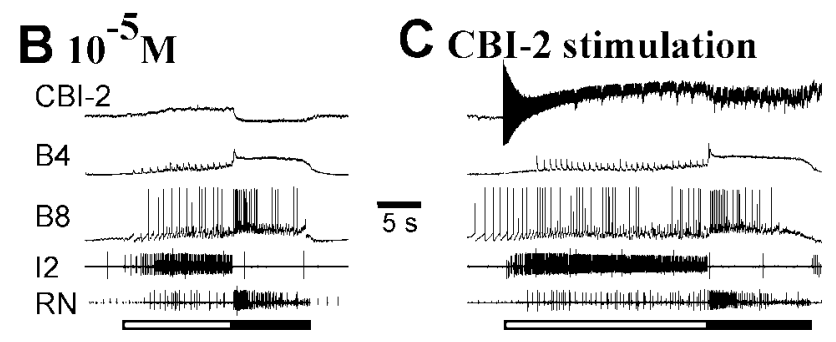

Figure 12. FCAP induces rhythmic feeding motor programs in an isolated cerebral-buccal preparation. A1, In control condition, the preparation was generally quiet, save that there was some spontaneous firing of radula closing motor neuron $\mathrm{B} 8$ and weak and irregular bursting activity in $\mathrm{I} 2$ nerve. $A 2$, After 3 min perfusion of $10^{-5} \mathrm{M}$ FCAPb, regular rhythmic feeding motor programs were initiated as rhythmic bursting was observed in I2 nerves and sustained depolarization was observed in B4. Each cycle of the motor programs consists of two phases: protraction and retraction. The protraction phase (open bar) is monitored by activity in I 2 nerve, and the retraction phase ( filled bar) is monitored by sustained depolarization of B4. The motor programs were ingestive because B8 was mostly active during the retraction phase. Note that CBI-2 was not active but did receive excitatory and inhibitory inputs during the protraction and retraction phase, respectively. $A 3$, After washout of FCAPb, the activity of the preparation returned to control, and no rhythmic motor programs were present. $B$, An expanded record of one of the feeding cycles shown in $A 2$ (between arrows) is plotted for comparison with a feeding cycle induced by CBI-2 stimulation $(C)$ in the same preparation (time scale is the same for $B$ and $C$.). The activity of neurons $\mathrm{B} 4, \mathrm{~B} 8$, and nerves I2, RN during the two feeding cycles elicited by FCAPb or CBI-2 stimulation is similar. The single spike in $\mathrm{B} 4(A 2, C)$ was clipped.

invertebrate nervous systems, these models systems are used extensively to gain insights into possible functions that neuropeptides play in feeding. Extensive research suggesting that peptides contribute to the functioning of neural circuits has been performed on invertebrate systems (Marder et al., 1995; Brezina and Weiss, 1997). Although many invertebrate neural circuits consist of a small number of neurons, such circuits are by no means simple in terms of cellular and molecular organization. One striking aspect of the complexity of small networks is the multitude of the modulatory inputs that may endow such circuits with their ability to generate multiple types of motor outputs. There has been a significant experimental and theoretical interest in determining how peptidergic modulatory actions contribute to various aspects of motor output plasticity. Importantly, the discovery of new neuropeptides has not only provided important insights into the cellular mechanisms of peptide actions but has also led to new conceptualizations in the organization of motor behaviors (Harris-Warrick and Marder, 1991; Weiss et al., 1992; Nusbaum et al., 2001).

To gain such insights through the study of peptide actions, the peptides that act on the neural circuits and peripheral tissues should be known. We used a system-oriented strategy that allowed us to identify and characterize a family of neuropeptides that induce rhythmic feeding motor output in Aplysia. This strategy took advantage of the fact that the CBCs fulfill a critical role in feeding behavior and that $\mathrm{CBC}$ s contain neuropeptides that act on the feeding circuitry (Sossin et al., 1987; Lloyd, 1989; Xin et al., 1999; Morgan et al., 2000, 2002; Jing and Weiss, 2001). MALDI analysis of the cut ends of the CBCs revealed a number of peaks, some of which are likely to represent novel peptides. Accumulation of peptides on different sides of the cut connectives gives an indication of their site of origin but cannot exclude origin outside the buccal and cerebral ganglia.

In invertebrates, multiple forms of related peptides are often encoded on a single precursor protein (Fujisawa et al., 1999; Furukawa et al., 2001). In some cases, the general organization of precursors is conserved between species (e.g., FMRFamide and myomodulin). To determine whether FCAP-related peptides were present in other species, we performed BLAST searches of GenBank. This search failed to detect related peptides. However, a recently published study (Nathoo et al., 2001) on C. elegans describes three families of neuropeptides (nlp-14, nlp-15, and nlp-5) that share a limited sequence similarity with the FCAPs of Aplysia. Given that this similarity is mostly at the variable $\mathrm{N}$-terminal and not the conserved C-terminal FCAP sequence, the FCAPs are likely to represent a family of neuropeptides distinct from these $C$. elegans neuropeptides. Additional work is necessary to determine the significance of these similarities and whether other FCAP-related peptides are present in mollusks and other phyla. At present we do not know which part of the FCAP peptide is responsible for its bioactivity. The FCAP precursor predicts a number of acidic peptides, but such peptides are often, although not always (Fan et al., 1997; Brezden et al., 1999), degraded and may function to compensate for the basic nature of the processing sites.

FCAP-containing neurons and processes are present not only in the cerebral and buccal ganglia but also in all other ganglia. Different ganglia are involved in distinct behaviors of the animal (Kandel, 1979), suggesting that FCAP may fulfill multiple behavioral functions. Indeed, FCAPs were abundant in the pleural and pedal ganglia. The strongly staining neuronal subcluster present in only the right pleural ganglion suggests that these neurons innervate asymmetrical structures, such as the penis or vagina. FCAPs are also expressed in all of the pleural sensory neurons, neurons that have been used as a model system to study the molecular mechanisms underlying learning and memory (Kandel, 1979) of defensive behaviors. FCAP was also detected with IMM and ISH but not with MALDI in the bag cells, a cluster of 
neurosecretory neurons that trigger egg-laying behavior. The failure of detecting FCAPs in the bag cells by MALDI may be attributable to analyte suppression by the extremely abundant egg-laying hormone precursor-derived peptides (Beavis and Chait, 1990; Li et al., 2000). Because the neuronal basis of reproductive and defensive behaviors is of significant interest to several research groups, determination of the structure of FCAPs and the localization of FCAPs to neurons involved in those behaviors may lead to experiments that will provide new insights into the generation of these behaviors.

In the current study, we focused on the role that FCAPs may play in the generation of feeding behavior. We found that the FCAPs are widely distributed within the feeding system of Aplysia. FCAP-containing neurons and processes could be observed in the buccal and cerebral ganglia and the gut. Furthermore, both MALDI and IMM detected FCAPs in the CBC, a nerve that contains axons of CBIs and BCIs, two classes of neurons that are implicated in initiation and modulation of feeding motor programs (Rosen et al., 1991; Teyke et al., 1993; Hurwitz et al., 1997, 1999; Xin et al., 1999; Sanchez and Kirk, 2000; Jing and Weiss, 2001). We showed that FCAPs are present in several CBIs and $\mathrm{BCIs}$, although the identity of these CBIs and BCIs remains to be defined. Because feeding behaviors require a coordinated action of the cerebral and buccal ganglia (Perrins and Weiss, 1996), the FCAPs may contribute to the coordinated activity of the two ganglia. We cannot exclude the possibility that FCAP-containing neurons in other ganglia contribute to feeding behavior.

In addition to the CBIs and BCIs, several neurons of the buccal ganglion were FCAP positive. We identified one of these as the glutamatergic (Klein et al., 2000a) mechanosensory neuron B21 (Rosen et al., 2000), which also contains two neuropeptide families, the SCPs (Miller et al., 1994) and enterins (Furukawa et al., 2001). B21 has been implicated in transforming biting-like to bite-swallow-like motor programs (Klein et al., 2000b; Rosen et al., 2000), a type of action that is common in both vertebrates and invertebrates and is referred to as a reflex modification of rhythmic behaviors. Such complex transformations require a coordinated modification of the phasing and duration of interneuron and motoneuron firing to assure a new coordinated motor output. The presence of a multitude of peptides in neuron B21 may be related to the multitude of actions that B21 exerts when it acts in reflex modification of feeding motor programs. Such a possibility may also be worth examining in higher animals.

Although several neuropeptides capable of modifying various features of Aplysia feeding motor programs have been identified, none are capable of initiating feeding-like motor programs. The FCAPs are unique in their ability to initiate motor programs and do so without activating the command-like neuron CBI-2. The targets of FCAP program-initiating actions remain to be identified. FCAPs-initiated buccal motor programs could be ingestive, egestive, or intermediate. Previous work has shown that neuropeptide APGWamide can bias motor programs toward ingestion (Jing and Weiss, 2001; Morgan et al., 2002), and neuropeptide ANPY can bias motor programs toward egestion (Kupfermann et al., 2001). Importantly, in contrast to the FCAPs, APGWamide and ANPY do not initiate motor programs. Taken together, these observations suggest that initiation and selection of specific motor programs may be under modulatory control of different neuropeptides. This is consistent with the idea that different neurons are responsible for initiation of motor programs and for specification of the nature of these programs (Jing and Weiss, 2001; Morgan et al., 2002). A recent study (Thirumalai and
Marder, 2002) demonstrated that different neuropeptides act on different CPG elements to elicit motor programs in crustaceans, suggesting that this may be a general principle of peptide actions in CPGs.

Although Aplysia feeding behaviors are normally under an accurate stimulus control (i.e., triggered with short latencies by application of food stimuli to the mouth), there are conditions when the feeding responses occur in the absence of food. Although spontaneous rhythmic feeding behaviors are rarely observed in the absence of a food stimulus (Kupfermann, 1974b), such responses are commonly observed in animals once they have been food-aroused. It remains unclear how normally stimuluscontrolled behaviors can become stimulus independent. It is appealing to hypothesize that the actions of FCAPs, which may be released when an animal encounters food, could be responsible for the generation of food-independent feeding responses. Our results suggest a hypothesis that the FCAPs may be important and unique components of intercellular signaling in the feeding circuitry and may contribute to the induction and persistence of food-induced arousal. Future studies of FCAP functions may provide insights into the general mechanism of neuropeptide action on neural circuitry to produce behavioral output.

\section{REFERENCES}

Beavis RC, Chait BT (1990) Rapid, sensitive analysis of protein mixtures by mass spectrometry. Proc Natl Acad Sci USA 87:6873-6877.

Brezden BL, Yeoman MS, Gardner DR, Benjamin PR (1999) FMRFamide-activated $\mathrm{Ca}^{2+}$ channels in Lymnaea heart cells are modulated by "SEEPLY," a neuropeptide encoded on the same gene. J Neurophysiol 81:1818-1826.

Brezina V, Weiss KR (1997) Analyzing the functional consequences of transmitter complexity. Trends Neurosci 20:538-543.

Brezina V, Bank B, Cropper EC, Rosen S, Vilim FS, Kupfermann I, Weiss KR (1995) Nine members of the myomodulin family of peptide cotransmitters at the B16-ARC neuromuscular junction of Aplysia. J Neurophysiol 74:54-72.

Church PJ, Lloyd PE (1994) Activity of multiple identified motor neurons recorded intracellularly during evoked feeding-like motor programs in Aplysia. J Neurophysiol 72:1794-1809.

Cropper EC, Tenenbaum R, Kolks MA, Kupfermann I, Weiss KR (1987) Myomodulin: a bioactive neuropeptide present in an identified cholinergic buccal motor neuron of Aplysia. Proc Natl Acad Sci USA 84:5483-5486.

Cropper EC, Miller MW, Tenenbaum R, Kolks MA, Kupfermann I, Weiss KR (1988) Structure and action of buccalin: a modulatory neuropeptide localized to an identified small cardioactive peptidecontaining cholinergic motor neuron of Aplysia californica. Proc Natl Acad Sci USA 85:6177-6181.

Cropper EC, Brezina V, Vilim FS, Harish O, Price DA, Rosen S, Kupfermann I, Weiss KR (1994) FRF peptides in the ARC neuromuscular system of Aplysia: purification and physiological actions. J Neurophysiol 72:2181-2195.

Eberwine JH, Valentino KL, Barchas JD (1994) In situ hybridization in neurobiology: advances in methodology. New York: Oxford UP.

Elmquist JK, Elias CF, Saper CB (1999) From lesions to leptin: hypothalamic control of food intake and body weight. Neuron 22:221-232.

Fan X, Croll RP, Wu B, Fang L, Shen Q, Painter SD, Nagle GT (1997) Molecular cloning of a cDNA encoding the neuropeptides APGWamide and cerebral peptide 1: localization of APGWamide-like immunoreactivity in the central nervous system and male reproductive organs of Aplysia. J Comp Neurol 387:53-62.

Floyd PD, Li L, Moroz TP, Sweedler JV (1999) Characterization of peptides from Aplysia using microbore liquid chromatography with matrix-assisted laser desorption/ionization time-of-flight mass spectrometry guided purification. J Chromatogr [A] 830:105-113.

Fujisawa Y, Furukawa Y, Ohta S, Ellis TA, Dembrow NC, Li L, Floyd PD, Sweedler JV, Minakata H, Nakamaru K, Morishita F, Matsushima O, Weiss KR, Vilim FS (1999) The Aplysia mytilus inhibitory peptiderelated peptides: identification, cloning, processing, distribution, and action. J Neurosci 19:9618-9634.

Furukawa Y, Nakamaru K, Wakayama H, Fujisawa Y, Minakata H, Ohta S, Morishita F, Matsushima O, Li L, Romanova E, Sweedler JV, Park JH, Romero A, Cropper EC, Dembrow NC, Jing J, Weiss KR, Vilim FS (2001) The enterins: a novel family of neuropeptides isolated from the enteric nervous system and CNS of Aplysia. J Neurosci 21:8247-8261. 
Garden RW, Moroz LL, Moroz TP, Shippy SA, Sweedler JV (1996) Excess salt removal with matrix rinsing: direct peptide profiling of neurons from marine invertebrates using matrix-assisted laser desorption/ionization time-of-flight mass spectrometry. J Mass Spectrom $31: 1126-1130$

Garden RW, Shippy SA, Li L, Moroz TP, Sweedler JV (1998) Proteolytic processing of the Aplysia egg-laying hormone prohormone. Proc Natl Acad Sci USA 95:3972-3977.

Harris-Warrick RM, Marder E (1991) Modulation of neural networks for behavior. Annu Rev Neurosci 14:39-57.

Hillenkamp F, Karas M, Beavis RC, Chait BT (1991) Matrix-assisted laser desorption/ionization mass spectrometry of biopolymers. Anal Chem 63:1193A-1203A.

Hurwitz I, Neustadter D, Morton DW, Chiel HJ, Susswein AJ (1996) Activity patterns of the B31/B32 pattern initiators innervating the I2 muscle of the buccal mass during normal feeding movements in Aplysia californica. J Neurophysiol 75:1309-1326.

Hurwitz I, Kupfermann I, Susswein AJ (1997) Different roles of neurons B63 and B34 that are active during the protraction phase of buccal motor programs in Aplysia californica. J Neurophysiol 78:1305-1319.

Hurwitz I, Perrins R, Xin Y, Weiss KR, Kupfermann I (1999) C-PR neuron of Aplysia has differential effects on "feeding" cerebral interneurons, including myomodulin-positive CBI-12. J Neurophysiol 81:521-534.

Jahan-Parwar B, Fredman SM (1976) Cerebral ganglion of Aplysia: cellular organization and origin of nerves. Comp Biochem Physiol [A] 54:347-357.

Jing J, Weiss KR (2001) Neural mechanisms of motor program switching in Aplysia. J Neurosci 21:7349-7362.

Kandel ER (1979) Behavioral biology of Aplysia: a contribution to the comparative study of opisthobranch molluscs. San Francisco: W. H. Freeman.

Kaufmann R (1995) Matrix-assisted laser desorption ionization (MALDI) mass spectrometry: a novel analytical tool in molecular biology and biotechnology. J Biotechnol 41:155-175.

Klein AN, Weiss KR, Cropper EC (2000a) Glutamate is the fast excitatory neurotransmitter of small cardioactive peptide-containing Aplysia radula mechanoafferent neuron B21. Neurosci Lett 289:37-40.

Klein AN, Eisenman JS, Weiss KR, Cropper EC (2000b) Changes in ingestive motor programs induced by stimulation of a single sensory neuron in Aplysia. Soc Neurosci Abstr 26:700.

Kupfermann I (1974a) Dissociation of the appetitive and consummatory phases of feeding behavior in Aplysia: a lesion study. Behav Biol 10:89-97.

Kupfermann I (1974b) Feeding behavior in Aplysia: a simple system for the study of motivation. Behav Biol 10:1-26.

Kupfermann I, Horn CC, Sweedler JV, Weiss KR, Jing J, Vilim FS (2001) Alimentary function and NPY peptide in Aplysia. Soc Neurosci Abstr 27:422.418.

Li L, Moroz TP, Garden RW, Floyd PD, Weiss KR, Sweedler JV (1998) Mass spectrometric survey of interganglionically transported peptides in Aplysia. Peptides 19:1425-1433.

Li L, Garden RW, Sweedler JV (2000) Single-cell MALDI: a new tool for direct peptide profiling. Trends Biotechnol 18:151-160.

Lloyd PE (1989) Interganglionic axonal transport of neuropeptides in Aplysia. J Neurosci 9:3243-3249.

Marder E, Christie AE, Kilman VL (1995) Functional organization of cotransmission systems: lessons from small nervous systems. Invert Neurosci 1:105-112.

Miller MW, Rosen SC, Schissel SL, Cropper EC, Kupfermann I, Weiss KR (1994) A population of SCP-containing neurons in the buccal ganglion of Aplysia are radula mechanoafferents and receive excitation of central origin. J Neurosci 14:7008-7023.

Morgan PT, Perrins R, Lloyd PE, Weiss KR (2000) Intrinsic and extrinsic modulation of a single central pattern generating circuit. J Neurophysiol 84:1186-1193.

Morgan PT, Jing J, Vilim FS, Weiss KR (2002) Interneuronal and peptidergic control of motor pattern switching in Aplysia. J Neurophysiol 87:49-61.

Morris HR, Panico M, Karplus A, Lloyd PE, Riniker B (1982) Elucidation by FAB-MS of the structure of a new cardioactive peptide from Aplysia. Nature 300:643-645.

Morton DW, Chiel HJ (1993a) The timing of activity in motor neurons that produce radula movements distinguishes ingestion from rejection in Aplysia. J Comp Physiol 173:519-536.

Morton DW, Chiel HJ (1993b) In vivo buccal nerve activity that distinguishes ingestion from rejection can be used to predict behavioral transitions in Aplysia. J Comp Physiol 172:17-32.
Nargeot R, Baxter DA, Byrne JH (1999) In vitro analog of operant conditioning in Aplysia. II. Modifications of the functional dynamics of an identified neuron contribute to motor pattern selection. J Neurosci 19:2261-2272.

Nathoo AN, Moeller RA, Westlund BA, Hart AC (2001) Identification of neuropeptide-like protein gene families in Caenorhabditis elegans and other species. Proc Natl Acad Sci USA 98:14000-14005.

Nielsen H, Engelbrecht J, Brunak S, von Heijne G (1997) Identification of prokaryotic and eukaryotic signal peptides and prediction of their cleavage sites. Protein Eng 10:1-6.

Nusbaum MP, Blitz DM, Swensen AM, Wood D, Marder E (2001) The roles of co-transmission in neural network modulation. Trends Neurosci $24: 146-154$.

Perrins R, Weiss KR (1996) A cerebral central pattern generator in Aplysia and its connections with buccal feeding circuitry. J Neurosci 16:7030-7045.

Perrins R, Weiss KR (1998) Compartmentalization of information processing in an Aplysia feeding circuit interneuron through membrane properties and synaptic interactions. J Neurosci 18:3977-3989.

Phares GA, Lloyd PE (1996) Purification, primary structure, and neuronal localization of cerebral peptide 1 from Aplysia. Peptides 17:753-761.

Phares GA, Walent JH, Niece RL, Kumar SB, Ericsson LH, Kowalak JA, Lloyd PE (1996) Primary structure of a new neuropeptide, cerebral peptide 2, purified from cerebral ganglia of Aplysia. Biochemistry 35:5921-5927.

Price DA, Greenberg MJ (1977) Structure of a molluscan cardioexcitatory neuropeptide. Science 197:670-671.

Rosen SC, Teyke T, Miller MW, Weiss KR, Kupfermann I (1991) Identification and characterization of cerebral-to-buccal interneurons implicated in the control of motor programs associated with feeding in Aplysia. J Neurosci 11:3630-3655.

Rosen SC, Miller MW, Evans CG, Cropper EC, Kupfermann I (2000) Diverse synaptic connections between peptidergic radula mechanoafferent neurons and neurons in the feeding system of Aplysia. J Neurophysiol 83:1605-1620.

Rubakhin SS, Li L, Moroz TP, Sweedler JV (1999) Characterization of the Aplysia californica cerebral ganglion $\mathrm{F}$ cluster. J Neurophysiol 81:1251-1260.

Sambrook J, Fritsch EF, Maniatis T (1989) Molecular cloning: a laboratory manual. Cold Spring Harbor, NY: Cold Spring Harbor Laboratory.

Sanchez JA, Kirk MD (2000) Short-term synaptic enhancement modulates ingestion motor programs of Aplysia. J Neurosci 20:RC85(1-7).

Seidah NG, Chretien M (1999) Proprotein and prohormone convertases: a family of subtilases generating diverse bioactive polypeptides. Brain Res 848:45-62.

Sossin WS, Kirk MD, Scheller RH (1987) Peptidergic modulation of neuronal circuitry controlling feeding in Aplysia. J Neurosci 7:671-681.

Spengler B (1997) Post-source decay analysis in matrix-assisted laser desorption/ionization mass spectrometry of biomolecules. J Mass Spectr 32:1019-1036.

Strand FL (1999) Neuropeptides: regulators of physiological processes. Cambridge, MA: MIT.

Teyke T, Rosen SC, Weiss KR, Kupfermann I (1993) Dopaminergic neuron B20 generates rhythmic neuronal activity in the feeding motor circuitry of Aplysia. Brain Res 630:226-237.

Thirumalai V, Marder E (2002) Colocalized neuropeptides activate a central pattern generator by acting on different circuit targets. J Neurosci 22:1874-1882.

Vilim FS, Price DA, Lesser W, Kupfermann I, Weiss KR (1996) Costorage and corelease of modulatory peptide cotransmitters with partially antagonistic actions on the accessory radula closer muscle of Aplysia californica. J Neurosci 16:8092-8104.

Vilim FS, Alexeeva V, Moroz LL, Li L, Moroz TP, Sweedler JV, Weiss KR (2001) Cloning, expression and processing of the CP2 neuropeptide precursor of Aplysia. Peptides 22:2027-2038.

Weiss KR, Brezina V, Cropper EC, Hooper SL, Miller MW, Probst WC, Vilim FS, Kupfermann I (1992) Peptidergic co-transmission in Aplysia: functional implications for rhythmic behaviors. Experientia 48:456-463.

Woods SC, Seeley RJ, Porte Jr D, Schwartz MW (1998) Signals that regulate food intake and energy homeostasis. Science 280:1378-1383.

Xin Y, Hurwitz I, Perrins R, Evans CG, Alexeeva V, Weiss KR, Kupfermann I (1999) Actions of a pair of identified cerebral-buccal interneurons (CBI-8/9) in Aplysia that contain the peptide myomodulin. J Neurophysiol 81:507-520. 